\title{
O olho e a letra
}

\author{
José Bento Machado Ferreira (Bolsista PIBIC/CNPq - DF/USP/SP) \\ Orientador: Carlos Alberto Ribeiro de Moura
}

Pensemos a correspondência entre as artes visuais e as da palavra na modernidade a partir da Confissão criadora, de Paul Klee e de $O$ olho e o espírito, de MerleauPonty. Lemos o texto do artista à luz do ensaio do filósofo ou será que é o primeiro que melhor ilustra as profundas reflexões do segundo? Se alguma conclusão vislumbrarmos será a de que este problema não tem solução, uma vez que os cernes de cada texto, embora de origens e naturezas distintas, conclamam um ao outro e se conjugam numa composição que não é definidora, mas esclarecedora das interpenetrações da literatura, da pintura e da filosofia no seio da criação artística.

O texto de Klee foi inicialmente destinado a uma publicação homônima que reunia depoimentos de artistas plásticos, músicos e escritores a respeito de sua atividade artística. Foi escrito no verão de 1918. O ensaio de Merleau-Ponty é sua última obra publicada em vida e é considerado o seu principal texto de Estética. Adianto que procuraremos mostrar que o seu alcance é bem mais amplo, pois nele o autor submerge no mundo nebuloso da criação artística e, sem misturar-se a ele, tem dele uma visão tão clara como poucas entre as que nos são oferecidas. O mergulho nas profundezas do visível traz à tona a mensagem, dirigida a todos, de uma nova articulação do homem com o Ser, a comunhão do intelecto com a carne, isto é, com o corpo do universo, à qual a arte não é mais do que uma das janelas, mas privilegiada por razões que tentaremos explicitar.

Ao falar numa articulação do homem com o Ser, surge a figura de Martin Heidegger, cuja influência vinha se exercendo cada vez mais sobre Merleau-Ponty no período final de sua vida. Para Heidegger, a obra de arte é uma abertura para o que antes dela era encoberto por um véu. Assim, os sapatos de uma camponesa pintada por Van Gogh destoam dos sapatos dados na experiência comum; no quadro eles contam sua história, no mundo, calam. O exemplo dado em $A$ origem da obra de arte atesta a fundação do ser na linguagem e a sua irrupção no mundo é resguardada à arte, ou à sua essência, que é a poesia. No mundo, os sapatos meramente são; no quadro, já não são eles mesmos, dizem e mostram algo "que há e que entretanto não é" A partir da idéia husserliana de um mundo da vida fundamental e pré-reflexivo que subjaz a todo gesto de significação, Merleau-Ponty parece querer fundar a linguagem no ser. O fundo não seria senão uma superfície à segunda potência e superficial é a procura do ser fora dele, "ailleurs", fora do que aí há. Por isso se abre $O$ olho e o espírito com a crítica do comprometimento da ciência a uma ontologia subjetivista, que pulveriza o objeto ao recusar-se a habitá-lo.

Tudo se passa como se a percepção despojada de prejuízos do mundo englobasse o mundo inteiro e fosse fonte inesgotável de sentido. É um milagre da expressão, não por ser incompreensível, posto que exercê-lo é tê-lo presente. Só não pode ser catalogado ou possuido. Pois o conhecimento que pretende possuir seu objeto supõe algum recanto em nossa mente onde se armazenam as idéias que temos das coisas. Ora, nem a expressão é uma coisa, assim como o quadro não é uma tela cheia 
de manchas, nem as coisas se transformam em idéias quando conhecidas. Basta lembrarmo-nos de como Wolfgang Köhler via o sistema de significações atrelado inexoravelmente à experiência imediata.

Assim, fundamental é a remissão ao que aí está. E no entanto, de forma a dissolver a atitude natural, realista; em direção à dimensão profunda pela qual todas as coisas se mostram como carne. A crítica à percepção multilada pela técnica é tributária de Heidegger, bem como a idéia de que a arte é detentora de uma nova ontologia. E a crítica à filosofia reflexiva, verdadeira no que nega a relação exterior do eu e do mundo, mas incapaz de atingir o originário, onde o elo natal entre um e outro se desenrola. Contudo, filosofia e arte se emaranham diferentemente num e noutro pensador. Merleau-Ponty procura uma filosofia implícita. Heidegger só encontra o seu próprio pensamento explicitado, após as destruições. Trata-se, em última instância, para Merleau-Ponty, não tanto de explorar uma abertura que leva além do ser, mas de diluir a distinção entre o que é (aí) e aquilo a que nos abre a arte. Pois o véu das aparências é para ele já desvelo, descoberta.

A linguagem indireta é como a convergência evolutiva: inexplicável. E por isso a fala, com que se manipula o ser, é sempre a fala do mundo. O paradigma geométrico da era clássica é substituído pelo paradigma lógico-ontológico de "hoje" A razão da mathesis nos é desencoberta por nosso contato a posteriori porque existe a arte. $O$ mínimo e o máximo, o olho e o espírito.

A arte é a imitação da vida, não porque a reproduza mas porque realiza o sentimento e nisto abre contato com o modo pré-reflexivo do ser que havia sido obscurecido pela ontologia da clareza desde a matematização da natureza com Galilei. $O$ mundo da vida jamais deixou, no entanto, de ser o fundamento implícito de toda filosofia. Por isso é que se pode ler Descartes através da ambigüidade de seu pensamento, a ontologia ora do existente ora do objeto, não apenas através da ordem das razões. Indireta e alusiva, também a filosofia é experiência acumulada, como a cultura. A criança aprende a falar imitando sons e não significando, isto é, a origem da fala e da linguagem remonta a esta abertura sem conceito ao sensível, ao ser. A arte é uma forma sofisticada de linguagem; não mais distante, mas mais íntima da origem. Por isso não pode ser considerada num quadro em que a alusividade é pensada como defasagem em relação à significação convencional.

Merleau-Ponty é genial falando de arte porque fala como um leigo. Ao desculpar-se por não poder levar sua reflexão ao nível de uma história da arte, fica claro que o que perde em objetividade, ganha em profundidade, podendo empregar, como o pintor no visível, o corpo inteiro das suas idéias livremente, posicionando-se mais adequadamente para obter, à sua maneira, uma visão melhor da mudança, do clássico ao moderno, do contato com o mundo. É o que nos revela o autor no momento de O olho e o espírito em que faz sua confissão criadora. "Simplesmente, uma vez que a potência, ou a força geradora das obras excede toda articulação positiva de causalidade e de filiação, não é ilegítimo que um profano, deixando falar a lembrança de alguns quadros e de alguns livros, diga como a pintura intervém nas reflexões e deponha o sentimento que tem de uma discordância profunda, de uma mutação nas articulações do homem e do Ser, quando ele confronta massivamente um universo de pensamento clássico com as pesquisas da pintura moderna. Tipo de história por contato que talvez não saia dos limites de uma pessoa, e que porém deve tudo à 
freqüentação dos outros..."2

É bem mais o sistema de significações que age como fala falada ou bagagem cultural no fundo das reflexões o que é interpelado, e não uma história da arte factual, objetiva. Assim pode ser lido o cartesianismo como fundo da pintura clássica, a explicitar-Ihe a ontologia. Por contraste ou contato vemos como as técnicas da perspectiva clássica supõem um conceito de espaço contínuo e infinito, extensão. A profundidade é mera dimensão ao lado de largura e altura, os objetos são dados pela distância, sem grandeza interna, mas encaixados à grandeza que lhes impõe o pensamento.

"Um cartesiano não se vê no espelho: ele vê um boneco, um 'fora' do qual tem todas as razões para pensar que os outros vêem de modo semelhante, mas que, não mais aos outros que a ele mesmo, não é uma carne. Sua 'imagem' no espelho é um efeito da mecânica das coisas; se ele aí se reconhece, se ele a acha 'semelhante' é o pensamento que tece este elo, a imagem especular não é nada dele" ${ }^{3}$ Como em Descartes a aparência e a coisa mesma são separadas, cumpre que intervenha a instância que as reune para que haja regularidade na percepção. Notadamente é tal instância o pensamento. Em Merleau-Ponty, ou na "ontologia de hoje" a aparência é carne e a carne é matéria viva. A corporalidade do mundo não é dada por uma operação do entendimento, pois não há algo como um mundo interior onde o mundo exterior toma figura, há um solo anterior à reflexão, apresentado pela própria reflexão, como interrogação do que é pré-reflexivo. Neste solo surge o sujeito, em meio às coisas e por meio delas constituído - nas coisas é pensado e percebido.

O acesso ao solo supõe uma segunda potência da visão na qual o percebido não é mero objeto sensível a ser decifrado por um código de idéias inatas supostamente armazenado em situação eletro-química numa nossa mente sem que o saibamos. A menção ao reflexo no espelho é uma remissão tácita aos estudos de psicologia infantil nos quais Merleau-Ponty dá ênfase à descoberta da imagem especular pela criança. Ela aprende a ver-se como os outros a vêem e simultaneamente aprende a aparecer para os outros como quer ser vista. Sua consciência de si, até então global, mesclada ao mundo como um grande eu, aproxima-se do corpo próprio, sem que esta passagem se dê por meio de uma operação intelectual ou significativa por parte dela. É contudo um ato de linguagem, um contato "linguageiro" com o mundo. A imagem especular passa a ser uma extensão do corpo, como um órgão destinado à "freqüentação dos outros" Por isso, carne.

Neste solo, liberado de olhares feitos pelo descompromisso com a linguagem natural, o pintor se surpreende sendo observado pela mata. "O que se chama de inspiração deveria ser tomado ao pé da letra: há verdadeiramente inspiração e expiração do Ser, respiração no Ser, ação e paixão tão pouco discerníveis que já não se sabe quem vê e quem é visto, quem pinta e quem é pintado. Diz-se que um homem nasceu no instante em que o que não era senão um visível virtual se faz de uma só vez visível para todos e para si. A visão do pintor é um nascimento contínuo"4

Mas o que vê o pintor moderno é compreendido por contato com o mundo clássico. Assim como em Husserl o esvaziamento de sentido das ciências européis é formulado a partir da matematização da natureza em Galilei, descobridor e encobridor, e do próprio Descartes, fundador da idéia de racionalismo objetivista, assim como dos motivos transcendentais que dele irrompem. É oportuna a menção a Husserl pois 
se trata em $O$ olho e o espírito de uma descrição do surgimento do mundo da vida, esquecido paulatinamente pelas ciências da natureza, nas transformações da pintura moderna, que ao deixar de lado a representação realista, afasta-se do que Husserl chamava de schlechthin, ou a coisa pura e simples, da atitude natural, e passa a operar sobre a carne.

"O espaço de Descartes é verdadeiro contra um pensamento submetido ao empírico e que não ousa construir. Era preciso antes idealizar o espaço, conceber este ser perfeito em seu gênero, claro, manejável e homogêneo, que o pensamento sobrevoa sem ponto de vista, e que articula inteiro em três eixos retangulares, para que se pudesse um dia encontrar os limites da construção, compreender que o espaço não tem três dimensões, nem mais nem menos, como um animal de quatro ou duas patas, que as dimensões são pré-determinadas pelas diversas métricas sobre uma dimensionalidade, um Ser polimorfo, que as jutifica a todas sem ser completamente exprimido por nenhuma. Descartes tinha razão em liberar o espaço. Seu erro foi erigí-lo num ser todo positivo, além de todo ponto de vista, de toda latência, de toda profundidade, sem nenhuma espessura verdadeira" ${ }^{5}$

O clássico é visto como preparação para os avanços da modernidade e não por defasagem, assim como viam os próprios clássicos aqueles que lhes antecediam. Isso porque a história não é contada por um sujeito desenraizado, mas encarnado no ponto de vista que a desenrola como uma fala ambígua e indireta, e não retilínea e progressiva. Por isso, mesmo na ontologia de Descartes, cumpre reconhecer não apenas sua "espuma de passado" mas também sua "crista de futuro"6 Pois em ondas os conceitos são jogados uns sobre os outros e a apreensão deste movimento é - que estabelece a verdadeira "meditação filosófica" para além da mera apreciação de suas formas fixas e sem sentido na cultura, segundo a ordem das razões. O filósofo não pode senão submergir no mundo da pintura, e como este outrora operava sobre o quadro do cartesianismo, inverte-se a figura e agora é a pintura o fundo da filosofia, nela implícita e ativa, jamais efetivada.

Na pintura moderna, a profundidade se desvencilha do sistema de três eixos, já não sendo obtida geometricamente, como distância em relação aum ponto abstratamente situado atrás da tela. O pintor encarna e, como entende o seu ofício como o contato e indivisão entre si e o ser (e de "artesão do Ser" o artista será chamado), tudo o que pinta, pinta-o em relação a si, de modo que o ponto onde se situa é como que retratado pela pintura simultaneamente, como um todo. A profundidade é um meio de exploração do mundo. Por meio dela a visão invade o visto e se faz nele. Já não é mera objetividade o que aparece: surge na aparência algo mais que não era visível, que só poderia ser visto por este pintor neste lugar. Um invisível é feito visível para todos. E, porque se dá na dimensão fundamental do Ser, não é a figura vaga do estado de espírito do autor o que se dá a ver. Esta figura vaga irrompendo pelas coisas ensina-nos a ver de outra maneira o mundo, qualquer que seja o estado de seu espírito.

É então a ontologia da profundidade como carne o que tem a pintura moderna a oferecer, como filosofia implícita. "Da profundidade assim compreendida, não se pode mais dizer que ela é 'terceira dimensão'. Antes de mais nada, se ela fosse uma, seria logo a primeira: não há formas, planos definidos, se não se estipula a que distância de mim se encontram suas diferente partes. (...) A profundidade assim compreendida 
é antes a experiência de uma reversibilidade das dimensões, de uma 'localidade' global onde tudo está de uma só vez, da qual altura, largura e distância são abstraídas, de uma voluminosidade que se exprime, numa palavra, dizendo que a coisa está aí" ${ }^{\prime \prime}$ A profundidade é a carne porque é através dela que, numa inspeção do corpo, a visão interroga o mundo e as coisas respondem, resistem ao olhar como se por ele tocadas. É então que todas as coisas aparecem como emanações do fundo primordial que está em toda e em nenhuma parte. Por meio deste fundo é que o corpo, não só do artista, mas do vidente, o que engloba autores e espectadores, é feito do mesmo estofo, do mesmo material que o mundo.

A noção de profundidade ganhou muita importância na obra de Merleau-Ponty, aparecendo em outros textos. Talvez tenha sido suscitada por Husserl. Eis o que diz Merleau-Ponty num curso sobre a fenomenologia, no Collège de France: "Não há um ça filosófico, um instinto ou uma vida transcendental - que não venha a ser vontade, filosofia só por meu esforço de Selbstdenker, e, que no passado sedimentado, não passam de anônimos "es", elo da intersubjetividade filosófica pelas suas costas, Ineinander que não é apreensível para cada um senão em sua solidão - A lebendige Geistigkeit oculta - tudo isso não se pode compreender por consciências paralelas em seus atos privados. Tiefensphäre, terceira dimensão, patente Flächenleben e latente Tiefenleben - a profundidade é caracterizada pelo paradoxo, o Widersinn" ${ }^{8}$ A profundidade, ou esfera de profundidade, é englobante de uma "vida rasa", que é patente, como o schlechthin da atitude natural, e de uma "vida funda" que é latente, é segunda potência. De uma a outra não se sai da mesma esfera, do mesmo mundo originário. Uma é latente à outra, assim como o invisível é latente ao visível e age sempre sobre a visão, mesmo irrompendo no visível só por meio do trabalho de arte.

A profundidade é tembém onde se dá a intersubjetividade filosófica, ou Ineinander, literalmente "um no outro", ou "um ao outro". Pelas costas da filosofia porque o seu lugar é a não-filosofia. Mesmo em Husserl a abertura aos outros é anterior à afirmação do mundo como mundo da vida. Antes dela o sujeito é Ego solipsis e o mundo está entre parênteses. Só por meio dos outros é que o mundo passa a ser percebido como carne. Assim também em Merleau-Ponty, em seus estudos da psicologia infantil, o eu da criança só habita o corpo próprio e deixa a consciência global por meio de sua inserção em meio aos outros. Também a fala é assim adquirida. A criança deixa o balbucio, o banho na linguagem, e passa a comunicarse efetivamente com os outros. Nisso desenvolve um estilo só seu de fazê-lo, de acordo com um Urbild que vinha sendo preparado desde as primeiras imitações de gestos e fonemas, antes da palavra, nos primórdios da linguagem.

A vida funda é a irrupção deste solo fundamental que persiste às costas da filosofia, mas não do homem natural. $A$ intersubjetividade está aí em frente, ativa. $A$ solidão do artista, na qual vê e é visto pelo mundo, nasce entre as coisas, e a do Selbstdenker, na qual suspende o juízo a respeito da existência, não são senão momentos destas experiências que são abertura para os outros, tendo em vista sempre sua expressão. "Nós nos situamos, como o homem natural, em nós e nas coisas, em nós e em outrem, no ponto em que, por um tipo de chiasma, nós nos tornamos os outros e nós nos tornamos mundo. A filosofia não é ela mesma a não ser que recuse as facilidades de um mundo de uma só entrada, assim como aquelas de um mundo de múltiplas entradas, todas acessíveis ao filósofo. Ela se dá, como o homem natural, 
no ponto em se faz a passagem do eu ao mundo e ao outro, na encruzilhada das avenidas"9

Assim como a consciência perceptiva é um pensamento não-convencional, nem da consciência clara e distinta nem do inconsciente irracional, mas sempre consciente e inconsciente, também o eu, o mundo e os outros se interpentram nesta vida funda, que na pintura é a segunda potência da visão. Diríamos que o eu, o mundo e os outros se interpenetram como a filosofia, a pintura e a literatura: reflexão, visão e fala. Nunca num ou noutro, mas um ao outro, na encruzilhada.

A filosofia, como busca do fundamental, tem a tarefa de perguntar pelas origens, o que abre a reflexão ao pré-reflexivo. Deve então preservar as coisas como estavam originalmente, isto é ater-se a este ponto de indiferença, a encruzilhada. Do contrário, lançaria sobre seus temas conceitos destinados a decifrar objetos. Não os deixaria falar. Fecharia os fenômenos como coisas antes de neles explorar sua abertura ao ser carnal. Merlau-Ponty o faz com maestria ao dar voz à ontologia da pintura, à vida funda, sem procurar a chave com a qual desvendar a história da arte. Após $\underline{O}$ olho $\mathrm{e}$ o espírito, a história da arte continua a ser um mistério e os quadros dos pintores ainda perguntam, como as palavras de Drummond: - trouxeste a chave? $\mathrm{E}$ as mil faces secretas de uma obra continuam a fluir pela face neutra: fosse removido o lacre e então seria escolhida uma só face, não haveria vida rasa e vida funda, mas apenas a objetividade, não haveria a arte.

Também entre as notas de $\underline{O}$ visível e o invisível há uma destinada à idéia de profundidade $^{10}$ É a "dimensão do oculto" justamente porque ao se tentar decifrar as coisas, deixa-se de vê-las. Há uma dialética sem síntese, ou antes um jogo do raso e do fundo, que faz com que a vida funda seja a das aparências apreendidas sem conceito no sensível, ou seja, superfície. Nas tentativas de determiná-las, são abstraídas do fundo carnal donde surgem. E fica-se no raso, ainda que com pretenso conhecimento objetivo. "É a dimensão por excelência do simultâneo". Porque espaço e tempo são um só movimento, ainda não recortaram o sensível. Há fluxo antes de deslocamento, antes de sucessividade, há duração. O olhar, graças à profundidade, não se resume nessa "zona móvel de nitidez" porque é a todo tempo o estabelecimento do mundo visível e do Ser. Assim como ao ler um livro todos os livros lidos são interpelados, tornam acessível o novo ao passo em que são transformados por ele, também o visível como um todo se transforma em cada olhar. Pela profundidade as visões "deslisam uma na outra e se integram"

"É ela então que faz com que as coisas tenham uma carne: vale dizer, opõem à minha inspeção obstáculos, uma resistência que é precisamente sua realidade, sua 'abertura' seu totum simup' O visível é, então, palpável.

Ou bem, é o homem mesmo que se expande ao se considerar pela profundidade sua estadia no mundo. "Cumpre tomar ao pé da letra o que nos ensina a visão: que por ela tocamos o sol, as estrelas, estamos ao mesmo tempo em toda parte, tanto ao pé das lonjuras quanto das coisas próximas, e que mesmo nosso poder de imaginarmo-nos alhures - 'Estou em Petesburgo em minha cama, em Paris, meus olhos vêem o sol' - de visar livremente, onde quer que estejam, seres reais, empenha ainda a visão, emprega meios que tomamos dela"11 Ora, se pela profundidade a visão amplia seu sentido, deixando de ser condicionada pelo pensamento em sua atividade, já menos tátil que palpável, permitindo ao pintor exprimir não apenas o 
cem mais que "se formaram" do que terem sido criadas, irradia a essência entre as palavras.

O espírito é o fundo primordial a partir do qual as coisas entram em conjunção. $O$ invisível, feito visível pelo olho, não é como um espírito subjetivo que se faz absoluto através do objetivo, ou o em si e o para si. O olho engloba o espírito, que é carne.

\section{BIBLIOGRAFIA}

Heidegger, Martin : Der Ursprung des Kunstwerkes, Reclam;

Klee, Paul: "Schöpferische Konfession" in Kunstlehre, Reclam;

Merleau-Ponty, Maurice: Notes des cours au Collège de France, Gallimard; L'oeil et l'esprit, Gallimard;

Le visible et l'invisible, Gallimard;

Nunes, Benedito: No tempo do niilismo, Ática.

\section{NOTAS}

1. Citado por Benedito Nunes, No tempo do niilismo, p 96.

2. O olho e o espirito, p 63.

3. Idem, pp 38 e 39.

4. lb. pp 31 e 32.

5. Ib. p 48.

6. Ib.p 62.

7. Ib.p 65.

8. Notas de Cursos, p 80.

9. O visivel e o invisível, p 212.

10. Idem, pp 272 e 273.

11. O olho e o espírito, $\mathrm{p} 85$.

12. Klee, Confissão criadora.

13. Notas de Cursos, p 189.

14. pp 69 e 70. 